\title{
Identification of Potential Phytoestrogen of Selected Compounds from Zingiber cassumunar Roxb. Rhizomes Using PharmMapper and Molecular Docking
}

\author{
Prasan Tangyuenyongwatana ${ }^{1, *} \mathbb{D}$, Wandee Gritsanapan ${ }^{2}$ \\ 1 College of Oriental Medicine, Rangsit University, Pathumthani, 12000, Thailand \\ 2 Phyto Product Research, 165 Soi Suwandee 3, Rimklongprapra Road, Bangsue, Bangkok 10800, Thailand; \\ wandee.gri@mahidol.ac.th (W.G) \\ * Correspondence: prasan.t@ rsu.ac.th;
}

Scopus Author ID 18839039900

Received: 6.06.2020; Revised: 30.06.2020; Accepted: 1.07.2020; Published: 4.07.2020

\begin{abstract}
Zingiber cassumunar Roxb. is a well-known medicinal herb in traditional medicines of South-East Asia for the treatment of inflammation. The therapeutic uses also include the treatment of primary dysmenorrhea and menstruation cycle irregularity. These activities may be attributed to the binding of receptors in the human body. In this research, reverse docking of compound D, dimethoxyphenylbutadiene (DMPBD), Trans-3-(3,4-dimethoxy-phenyl)-4-[(E)-3',4'-dimethoxystyryl]cyclohex-1-ene (Tran-1) and Trans-3-(4-hydroxy-3-methoxy-phenyl)-4-[(E)-3',4'-dimethoxystyryl]cyclo-hex-1-ene (Tran-2) which are chemical compounds found in the rhizomes of this plant were subjected to PharmMapper web server. The results showed carbonic anhydrase 2 and estrogen receptors as likely targets for compound D and DMPBD. The molecular docking of the four compounds was conducted with AutoDock Vina in PyRx 0.8 suite, and the binding energies of compound D and DMPBD on carbonic anhydrase 2 were found at a moderate level $(-5.2$ to $-5.3 \mathrm{kcal} / \mathrm{mol})$. For estrogen receptors, compound D and DMPBD exhibited a fair, binding pattern and energy (-6.2 to $-6.9 \mathrm{kcal} / \mathrm{mol})$. In comparison, Tran- 1 and Tran-2 showed better binding pattern and energy in estrogen- $\alpha$ (1A52) (-6.9 to $-7.5 \mathrm{kcal} / \mathrm{mol})$ than in estrogen- $\beta(1 \mathrm{X} 7 \mathrm{~J})(-4.1$ to $-5.7 \mathrm{kcal} / \mathrm{mol})$. We concluded that there was a correlation between selected phytoestrogen compounds and estrogen receptors.
\end{abstract}

Keywords: Phytoestrogen; Zingiber cassumunar; PharmMapper; AutoDock Vina; Estrogen receptor. (C) 2020 by the authors. This article is an open-access article distributed under the terms and conditions of the Creative Commons Attribution (CC BY) license (https://creativecommons.org/licenses/by/4.0/).

\section{Introduction}

Zingiber cassumunar Roxb. is a medicinal plant that is widely used as an antiinflammatory and pain-relieving agent in South-East Asia [1, 2]. It is one of the components in Prasaplai, a traditional Thai formula that comprises ten medicinal plants. The formula is composed of $50 \%$ Z. cassumunar rhizome powder, and the rest are equal amounts of the pericarps of Citrus hystrix DC., the roots of Acorus calamus L., the bulbs of Allium sativum L., the bulbs of Eleutherine americana (Aubl.) Merr. ex K. Heyne, the fruits of Piper nigrum L., the fruits of Piper retrofractum Vahl, the rhizomes of Zingiber officinale Roscoe and Curcuma zedoaria Roscoe, the seeds of Nigella sativa L., and sodium chloride and camphor. This herbal preparation is used to treat pain in primary dysmenorrhea and adjust the menstruation cycle [3, $4,5]$. The anti-inflammatory activity of the preparation has been extensively studied due to the cyclooxygenase- 2 inhibition effect of the main compounds. 
Polypharmacology, a concept that states that one compound may have more than one pharmacological targets. The concept can be used to explain the mechanism and therapeutic activities of traditional preparations to validate the therapeutic claims [6,7]. Inverse/reverse docking is a technique that uses a database of known targets and performs a screening of a compound with hundreds to thousands of protein structures to find the best binding [8, 9]. This technique can be used to reveal other pharmacological targets. PharmMapper online tool is a free accessed webserver establishing in 2010 and serves as an engine to identify candidate target of ligand or small molecule by using reverse pharmacophore matching approach[10]. The target pharmacophores of PharmMapper have more than 23,236 proteins covering 16,159 druggable pharmacophore models and 51,431 ligandable pharmacophore models. On the contrary, focused docking or normal docking is a tool to fine-tune ligand with the target protein to find the native binding conformation and protein-ligand interaction. There are several protein-ligand docking programs available and have been steadily increasing over the last decades. Among all these software, PyRx 0.8 virtual screening tool is a free program that performs molecular docking with AutoDock and AutoDock Vina as docking engines with reliable docking algorithms, good graphic user interface (GUI) and widely accepted [11, 12].

Estrogen receptors (ERs) are a member of the nuclear receptor family involving in the regulation of various physiological functions such as the reproductive system and bone homeostasis. Estrogen (17 $\beta$-estradiol) binding to ERs induces the transcription of the ER into the nucleus, which leads to the transactivation of the target gene [13]. ERs have two different forms, which are $\operatorname{ER} \alpha$ and $\operatorname{ER} \beta[14,15]$. ER $\alpha$ is mainly expressed in the mammary gland, uterus, ovary (thecal cell), and bone, while ER $\beta$ is mainly found in the ovary (granulosa cells), bladder, colon, and immune system.

The objective of this research is to identify the potential phytoestrogen of selected compounds, compound D, DMPBD, Tran-1, and Tran-2, from Z. cassumunar rhizomes by using PharmMapper and PyRx 0.8 virtual screening tool as docking engines. The result could potentially correlate phytoestrogen in the formula with the therapeutic claim of adjusting the menstruation cycle of the traditional Prasaplai preparation.

\section{Materials and Methods}

\subsection{Targets fishing by PharmMapper.}

The 2D structures of DMPBD, Compound D, Tran-1, and Tran-2 were drawn by ChemSketch (www.adclabs.com) in mol format. Then the 2D structures were converted to 3D structures using the Avogadro program (www.avogadro.cc) and saved in mol2 format. All mol2 compounds were subjected to PharmMapper web site (www.lilabecust.cn/pharmmapper). The screening results were sent back in a few days and showed a therapeutic drug target according to the parametric scores in the PharmMapper system.

\subsection{Molecular docking.}

PyRx 0.8 Virtual Screening Tool was selected as a docking program with AutoDock Vina as a docking engine. For docking procedure, carbonic anhydrase 2 protein (PDB ID: $1 \mathrm{BNV}$ ), estrogen- $\alpha$ (PDB ID: 1A52), and estrogen- $\beta$ (PDB ID: 1X7J) were loaded onto the program. Next, the ligands, DMPBD, Compound D, Tran-1, and Tran-2 were imported into the program, and all compounds were converted to pdbqt format. The grid box was drawn to cover the active site of the protein with co-ordination and box dimension, as shown in Table 1. 
The exhaustiveness values of all docking were set to 8 . The docking results were obtained in pdb files, which were overlay with crystal ligand structure of a protein using Discovery Studio Visualizer $\mathrm{v}$ 17.2.0. The colors in the 2D protein-ligand interaction in the pictures were assigned as follows: Green $=$ conventional hydrogen bonding, Light green $=$ weak hydrogen bond, Purple = pi-pi interaction, Pink = hydrophobic interaction alkyl-alkyl or pi-alkyl, Red = unfavorable hydrogen bond, and Yellow = pi-sulfur.

Table 1. The Center of co-ordinate of the binding site and box dimension.

\begin{tabular}{c|c|c} 
Proteins (PDB ID) & $\begin{array}{c}\text { Center co-ordinate } \\
(\mathbf{x}, \mathbf{y}, \mathbf{z})\end{array}$ & Box dimension (亡்) \\
\hline 1BNV & $-4.52 \times 4.77 \times 13.89$ & $25 \times 25 \times 25$ \\
\hline 1A52 & $106.85 \times 14.91 \times 96.51$ & $25 \times 25 \times 25$ \\
\hline 1X7J & $29.82 \times 36.06 \times 39.05$ & $25 \times 25 \times 25$
\end{tabular}

\section{Results and Discussion}

\subsection{Pharmmapper reverse screening.}

Pharmmapper is a web server that uses reverse pharmacophore matching approach for screening technique. From the screening results, compound D and DMPBD obtained the potential targets with fit screening scores, as shown in Tables 2 and 3.

Table 2. Compound D potential targets with fit score screened by PharmMapper.

\begin{tabular}{c|l|l|l} 
Rank & PDB ID & Target name & Fit score \\
\hline 1 & 1IF4 & Carbonic anhydrase 2 & 2.969 \\
\hline 2 & 2ZXC & Estrogen-related receptor gamma & 2.879 \\
\hline 3 & 1ZUC & Progesterone receptor & 2.837 \\
\hline 4 & $1 \mathrm{~W} 8 \mathrm{~L}$ & Peptidyl-prolyl cis-trans isomerase A & 2.834 \\
\hline 5 & $1 \mathrm{M} 3 \mathrm{D}$ & Purine nucleoside phosphorylase & 2.793
\end{tabular}

Table 3. The DMPBD potential targets with fit scores screened by PharmMapper.

\begin{tabular}{c|l|l|c} 
Rank & PDB ID & Target name & Fit score \\
\hline 1 & 3DBU & Carbonic anhydrase 2 & 2.903 \\
\hline 2 & 3BMP & Bone morphogenetic protein 2 & 2.897 \\
\hline 3 & 2PIR & Androgen receptor & 2.862 \\
\hline 4 & 3EQM & Cytochrome P450 19A1 & 2.823 \\
\hline 5 & 2OCF & Estrogen receptor & 2.818
\end{tabular}

Both compound D and DMPBD had the highest fit score for carbonic anhydrase 2 with values of 2.969 and 2.903, respectively. Carbonic anhydrase 2 is a group of enzymes that catalyze the reversible hydration of carbon dioxide to form bicarbonate ion and proton [16]. They regulate many roles in the body, such as $\mathrm{pH}$ regulation, bone reabsorption, fatty acid metabolism, gas exchange, and ion transport [17]. For compound D, the second target from PharmMapper was estrogen-related receptor gamma, and progesterone receptor was ranked third. On the other hand, the estrogen receptor was ranked fifth for DMPBD. These results revealed that these two compounds may perform an important role in the female sex-hormones and may be linked to the traditional use and therapeutic claims of adjusting the menstruation cycle.

Tran-1 and Tran-2 showed the highest target as caspase 7 protein and other various proteins where estrogen receptor had a lower affinity. The large sizes of these two compounds may not be favored by the rigid proteins during the docking process. In this study, we focus on estrogen-related to therapeutic activity, and we were not pursued other targets at this time. 


\subsection{Molecular docking results.}

The docking experiments were performed with PyRx 0.8 virtual screening tool with AutoDock Vina as a docking engine. The binding energies of each compound were shown in Table 4.

Table 4. Binding energies of compounds with target receptors.

\begin{tabular}{|c|c|c|}
\hline Proteins & Ligands & Binding energy (kcal/mol) \\
\hline \multirow{2}{*}{$\begin{array}{c}\text { Carbonic anhydrase } 2 \\
(1 \mathrm{BNV})\end{array}$} & Compound D & -5.3 \\
\hline & DMPBD & -5.2 \\
\hline \multirow[t]{4}{*}{ Estrogen- $\alpha$ (1A52) } & Compound D & -6.3 \\
\hline & DMPBD & -6.2 \\
\hline & Tran-1 & -6.9 \\
\hline & Tran-2 & -7.5 \\
\hline \multirow[t]{4}{*}{ Estrogen- $\beta(1 \mathrm{X} 7 \mathrm{~J})$} & Compound D & -6.9 \\
\hline & DMPBD & -6.7 \\
\hline & Tran-1 & -4.1 \\
\hline & Tran-2 & -5.7 \\
\hline
\end{tabular}

3.2.1. Docking DMPBD, Compound D against carbonic anhydrase $2(1 \mathrm{BVN})$.

The protein-ligand interaction of crystal structure of 1BVN showed the essential binding amino acids, including GLN92, HIS94, VAL121, PHE131, LEU198, THR199, and TRP209 (Figure 1). Threonine (THR199) and glutamine (GLN92) showed a hydrogen bonding with sulfoxide oxygen of ligand while histidine (HIS94) established hydrophobic interaction with an aromatic ring. Leucine (LEU198) showed pi-alkyl interaction.

Compound D showed an interaction between the hydroxy proton and zinc ion in the carbonic anhydrase 2 enzyme. This compound also exhibited threonine (THR199) and glutamine (GLN92) interaction with the oxygen in the molecule (Figure 2A). The other two amino acids, valine (VAL121) and leucine (LEU198), had the same interaction as that of the crystal ligand. Therefore, we concluded that compound D could bind with carbonic anhydrase 2 enzyme. For DMPBD, the interaction of amino acids in the active sites was less strong than that of compound D (Figure 2B). All of the interactions were a hydrophobic force, which was not a strong binding.
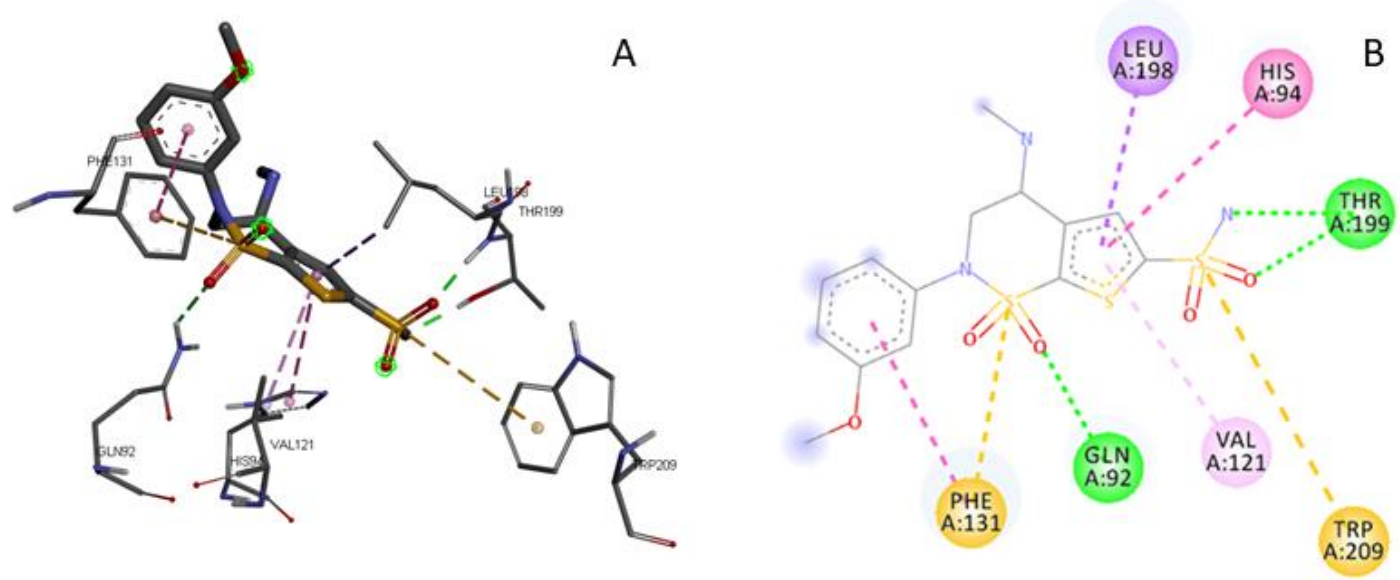

Figure 1. Protein-ligand complex interaction inside the active site (1BNV) (A) and 2D diagram of ligand interaction with crucial amino acids (B). 


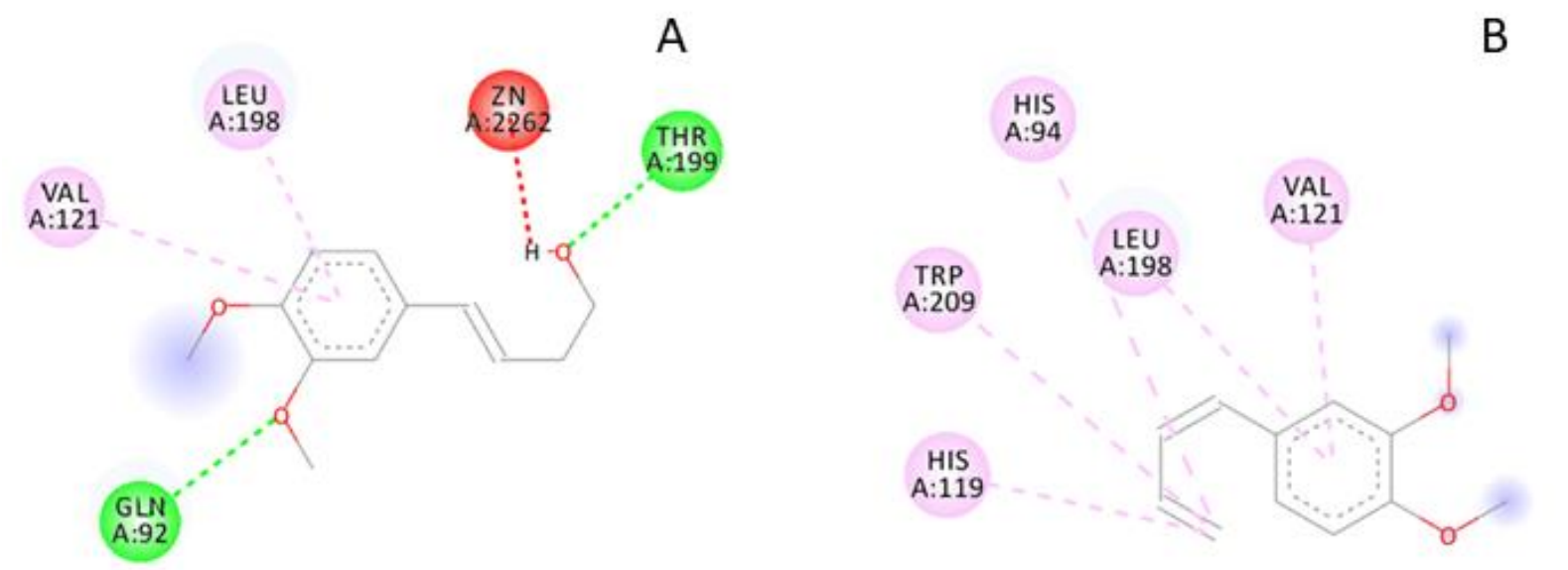

Figure 2. Amino acid interactions with compound D in 1BNV (A) and DMPBD in 1BNV (B).

3.2.2. Docking DMPBD, Compound D, Tran-1, and Tran-2 against estrogen- $\alpha$ (1A52).

For estrogen- $\alpha, 1 \mathrm{~A} 52$ was chosen as a receptor for docking. The protein-ligand (17 $\beta$ estradiol) interaction of crystal structure of 1A52 showed the essential binding amino acids, including LEU346, ALA350, GLU353, LEU384, LEU387, MET388, ARG394, LEU391, PHE404, ILU424, HIS524 and LEU525 (Figure 3).

Compound D showed an interaction between the hydroxy proton and zinc ion in the estrogen- $\alpha$ enzyme. This compound showed a leucine (LEU387) hydrogen bonding interaction with proton on the hydroxy group (Figure 4A). The other two amino acids, leucine (LEU346) and alanine (LEU350), exhibited hydrophobic interaction with phenyl ring of compound D. We concluded that compound D could bind with an estrogen- $\alpha$ enzyme. For DMPBD, the five interactions of amino acids in the active sites have occurred. Four of them were hydrophobic interactions, which were the same binding interaction as $17 \beta$-estradiol and one hydrogen bonding with threonine (THR347) (Figure 4B).
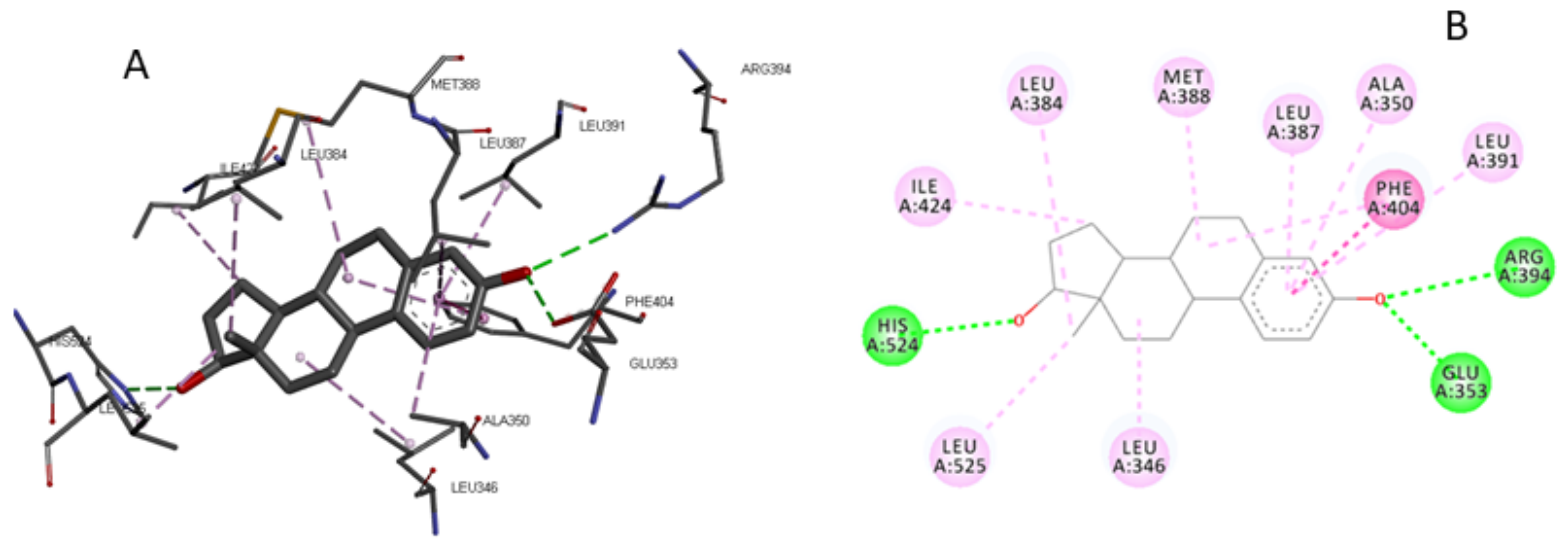

Figure 3. Protein-ligand complex interaction inside the active site (1A52) (A) and 2D diagram of ligand interaction with crucial amino acids (B). 

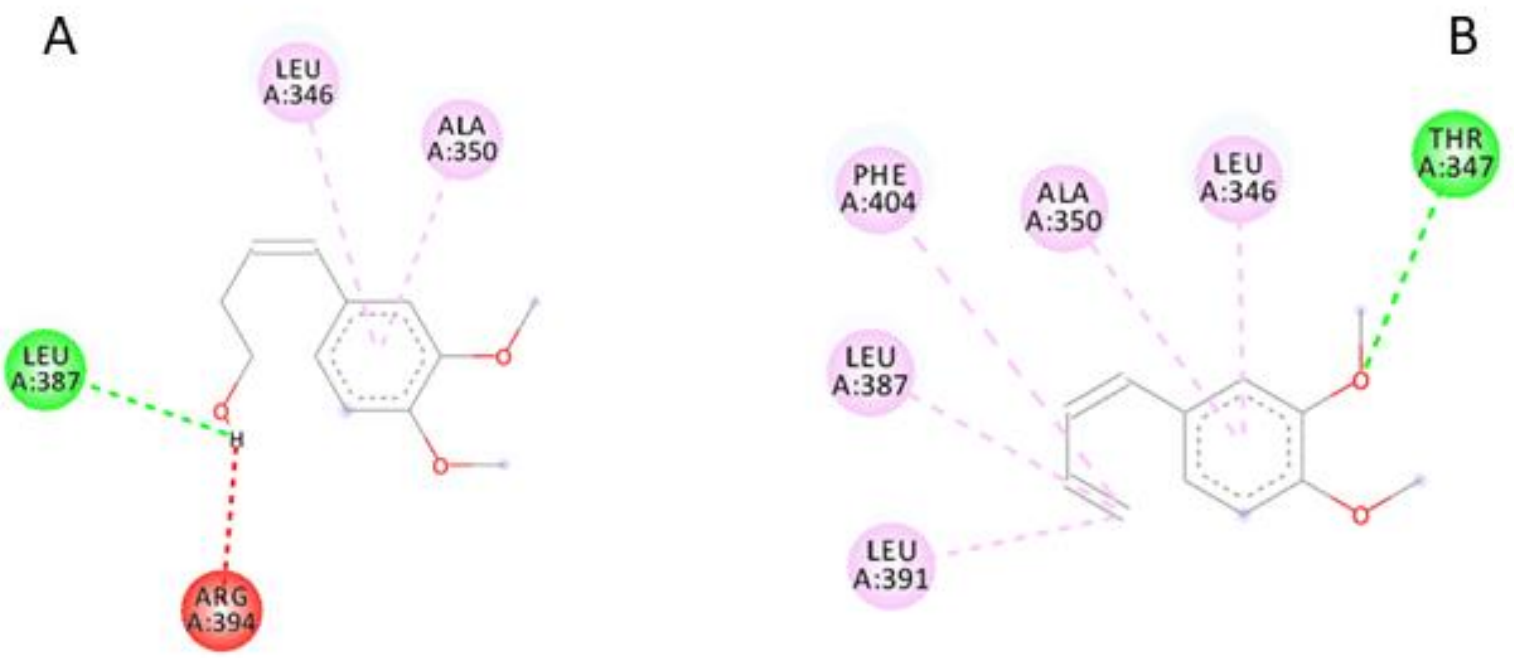

Figure 4. Amino acid interactions with compound D in 1A52 (A) and DMPBD in 1A52 (B).

For Tran-1, most interactions between receptors and ligands were hydrophobic interaction and pi-alkyl interaction. The positions of amino acid interaction can be divided into two sides, which were HIS524, ILE424 on the left-hand side, and ALA350, PHE404, LEU387, LEU391, MET388 on the other side (Figure 5A). This binding conformation stabilized the protein-ligand complex. In addition, Tran-2 had a stronger binding than Tran-1 because of the hydrogen bonding between the hydrogen of the methoxy group with GLU353, which was a crucial position in the active site (Figure 5B). The stronger binding resulted in the lower binding energy of Tran-2 $(-7.5 \mathrm{kcal} / \mathrm{mol})$ than Tran-1 $(-6.9 \mathrm{kcal} / \mathrm{mol})$. Due to the number of interactions of two compounds with receptors, Tran compounds can activate estrogen- $\alpha$ better than compound D and DMPBD.
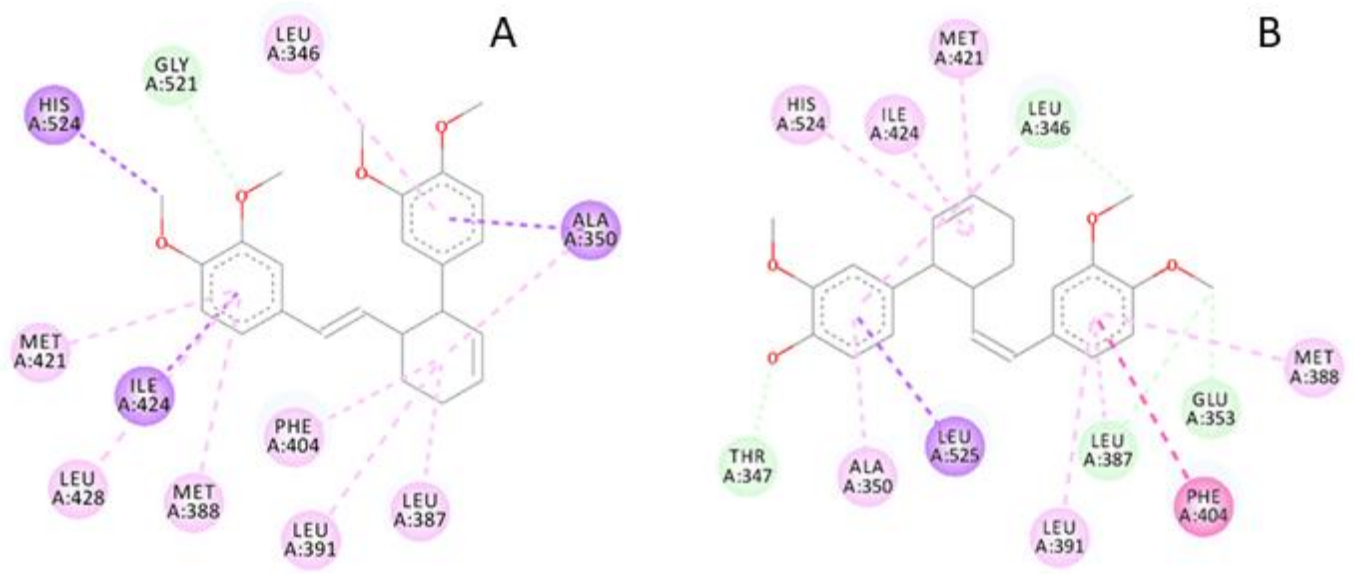

Figure 5. Amino acid interactions with Tran-1 in 1A52 (A) and Tran-2 in 1A52 (B).

3.2.3. Docking DMPBD, Compound D, Tran-1, and Tran-2 against estrogen- $\beta$ (1X7J).

For estrogen- $\beta$, 1X7J was chosen as a receptor for docking. The protein-ligand (Genisteine) interaction of crystal structure of $1 \mathrm{X} 7 \mathrm{~J}$ showed the essential binding amino acids, which were LEU298, ALA302, GLU305, LEU339, ARG346, LEU343, PHE356, HIS475 and LEU 476 (Figure 6). GLU305, ARG346, and HIS475 were the main crucial amino acids for this enzyme and were the same as those in estrogen- $\alpha$. 


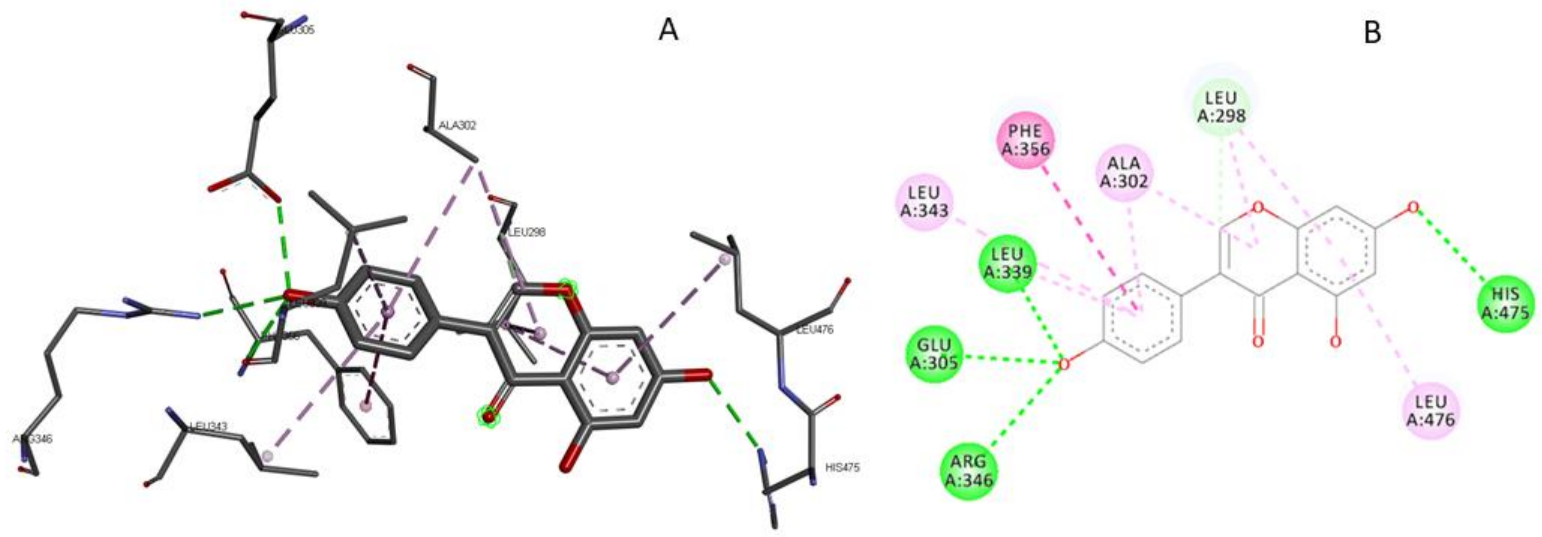

Figure 6. Protein-ligand complex interaction inside the active site (1X7J) (A) and 2D diagram of ligand interaction with crucial amino acids (B).

Compound D showed an interaction between the hydroxy proton and ARG346 in the estrogen- $\beta$ enzyme instead of interacting with a zinc atom in an enzyme. This compound had a glutamic acid (GLU305) hydrogen bonding interaction with the proton on the hydroxy group. Furthermore, leucine (LEU339) displayed hydrophobic interaction with the phenyl ring of compound D (Figure 7A). For DMPBD, the five interactions of amino acids in the active site have occurred. Four of them were hydrophobic interactions that were the same binding interaction as crystal ligand of 1X7J and one Pi-alkyl interaction with leucine (LEU298) (Figure 7B). The binding energy ranged from -6.7 to $-6.9 \mathrm{kcal} / \mathrm{mol}$. We concluded that compound D and DMPBD could bind with the estrogen- $\beta$ receptor.
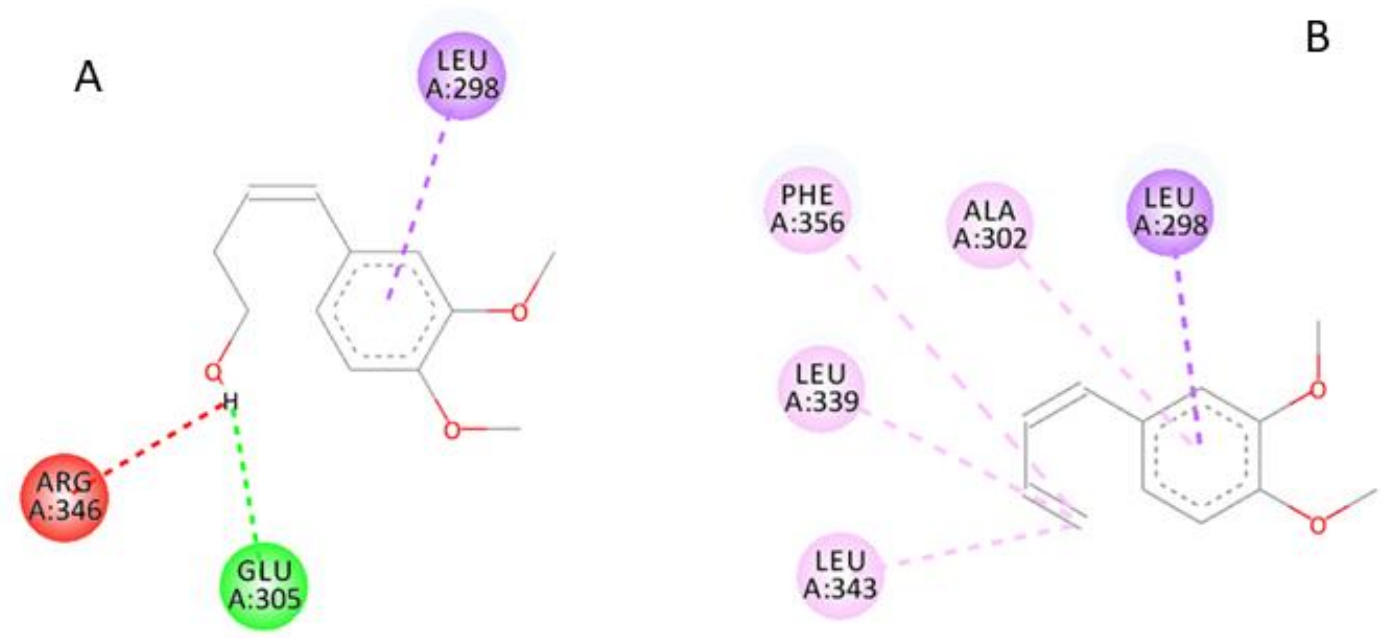

Figure 7. Amino acid interactions with compound D in 1X7J (A) and DMPBD in 1X7J (B).

Tran- 1 and Tran- 2 had almost the same binding interactions with estrogen- $\beta$. However, the number of interactions were less than those in estrogen- $\alpha$ and had crucial amino acid (GLU305) only on one side of the molecule, resulting in a less stable binding (Figure 8). The energies of both compounds were -4.1 to $-5.7 \mathrm{kcal} / \mathrm{mol}$ in $1 \mathrm{X} 7 \mathrm{~J}$, which lower than binding with 1 A52 (-6.9 to $-7.5 \mathrm{kcal} / \mathrm{mol})$. There was a report in diarylheptanoids from Curcuma comosa demonstrating transcriptional activation of both estrogenic targets, Bcl-xL, and ER- $\beta$ gene expression [18]. From the results, we demonstrated a docking experiment, and the selected diarylheptanoids showed the same amino acid interaction between ligand and amino acids in the active site of estrogen receptor when compared to 17ß-estradiol [19]. 

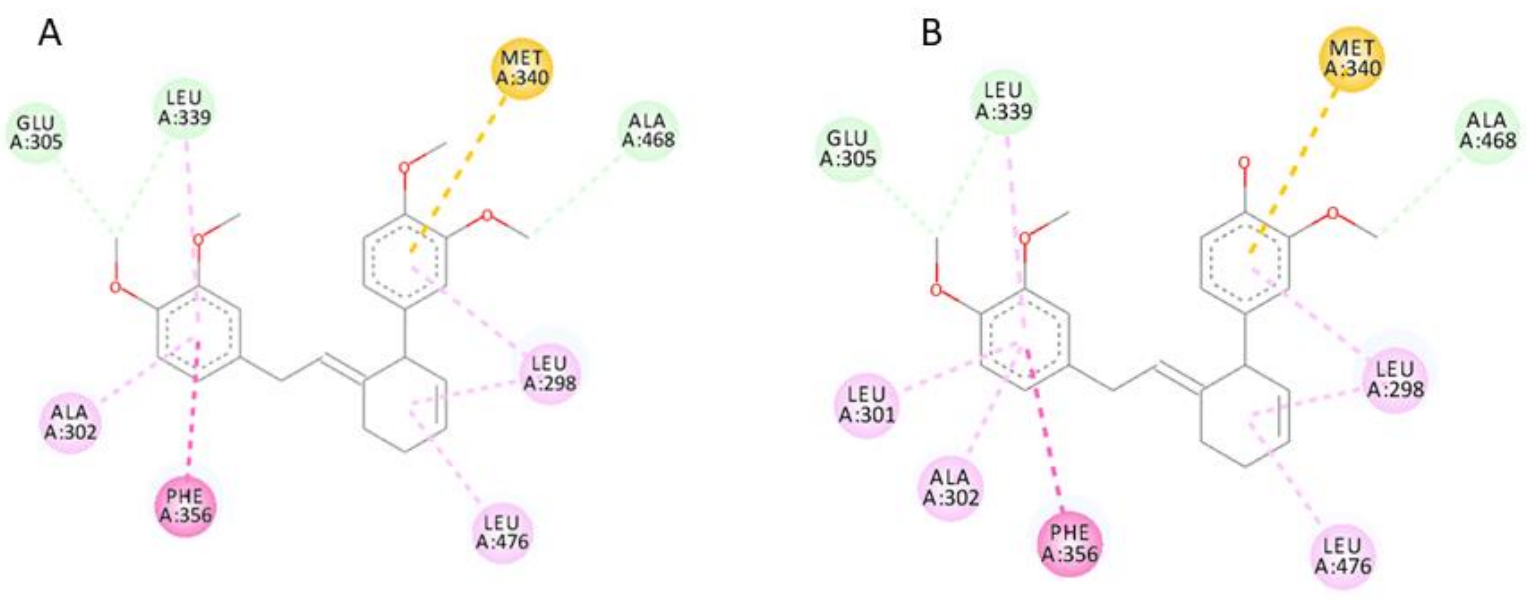

Figure 8. Amino acid interactions with Tran-1 in 1 X7J (A) and Tran-2 in 1 X7J (B).

\section{Conclusions}

In this study, potential targets of compound D and DMPBD, which are the major compounds in Z. cassumunar, were identified using the PharmMapper reverse pharmacophore matching approach and confirmed via molecular docking using AutoDock Vina. PharmMapper results identified carbonic anhydrase 2 as top ranking for both compounds. However, the estrogen receptor was also the target of these compounds. Tran- 1 and Tran- 2 from $Z$. cassamunar were also tested by docking with estrogen- $\alpha$ and estrogen- $\beta$ receptors. They showed potential binding with estrogen receptors. Further study is necessary to determine their precise interaction using in silico tools [20]. This study demonstrated that virtual screening using PharmMapper and computational molecular docking is a useful strategy to identify target protein and find the mechanism of action of compounds to validate therapeutic activities.

\section{Funding}

This research received no external funding.

\section{Acknowledgments}

This work was supported by the College of Oriental Medicine for computer and data storage. We thank Dr. Panupon Khumsupan for his kind proofreading of the manuscript.

\section{Conflicts of Interest}

The authors declare no conflict of interest.

\section{References}

1. Han, A.R.; Kim, M.S.; Jeong, Y.H.; Lee, S.K.; Seo, E.K. Cyclooxygenase-2 inhibitory phenylbutanoids from the rhizomes of Zingiber cassumunar. Chemical Pharmaceutical Bulletin (Tokyo) 2005, 5, 1466-1468, https://doi.org/10.1248/cpb.53.1466.

2. Li, M.; Bai, X.; Ma, Y.; Zhang, H.; Nama, N.; Pei, S.; Du, Z. Cosmetic potentials of extracts and compounds from Zingiber cassumunar Roxb. Rhizhome. Industrial Crops and Products 2019, 141, https://doi.org/10.1016/j.indcrop.2019.111764.

3. Tangyuenyongwatana, P.; Gritsanapan, W. Quantitative analysis and toxicity determination of artifacts originated in a Thai traditional medicine Prasaplai. Pharmaceutical Biology 2010, 48, 584-588, https://doi.org/10.3109/13880200903214223. 
4. Vannabhum, M.; Poopong, S.; Wongwananuruk, T.; Nimmannit, A.; Suwannatrai, U.; Dangrat, C.; Apichartvorakit, A.; Booranasubkajorn, S.; Laohapand, T.; Akaraserenont, P. The efficacy of Thai herbal Prasaplai formula for treatment of primary dysmenorrhea: A short-term randomized controlled trial. Evidence-Based Complementary and Alternative Medicine 2016, 2016, 7, https://doi.org/10.1155/2016/2096797.

5. Phimarn, W.; Sunthong, B.; Saramunee, K. Efficay of Prasaplai for treatment of primary dysmenorrhea: a Meta-Analysis. Research Journal of Pharmacognosy 2019, 6, 71-80, https://doi.org/10.22127/RJP.2018.80375.

6. Chaudhari, R.; Tan, Z.; Huang, B.; Zhang, S. Computational polypharmacology: a new paradigm for drug discovery. Expert Opinion on Drug Discovery 2017, 12, 279-291, https://doi.org/10.1080/17460441.2017.1280024.

7. Bologneri, M.L. Harnessing polypharmacology with medicinal chemistry. ACS Medicinal Chemistry Letters 2019, 10, 273-275, https://doi.org/10.1021/acsmedchemlett.9b00039.

8. Zhang, H.; Pan, J.; Wu, X.; Zuo, A.; Wei, Y.; Ji, Z. Large-scale target identification of herbal medicine using a reverse docking approach. ACS Omega. 2019, 4, 9710-9719, https://doi.org/10.1021/acsomega.9b00020.

9. Wang, F.; Wu, F.X.; Li, C.Z.; Jia, C.Y.; Su, S.W.; Hao, G.F.; Yang, G.F. ACID: a free tool for drug repurposing using consensus inverse docking strategy. Journal of Cheminformatic 2019, 11, https://doi.org/10.1186/s13321-019-0394-Z.

10. Wang, X.; Shen, Y.; Wang, S.; Li, S.; Zhang, W.; Liu, X.; Lai, L.; Pei, J.; Li, H. PharmMapper 2017 update: a web server for potential drug target identification with a comprehensive target pharmacophore database. Nucleic Acids Research. 2017, 45, W356-W360, https://doi.org/10.1093/nar/gkx374.

11. Dallakyan, S.; Olson, A.J. Small-molecule library screening by docking with PyRx. Methods in Molecular. Biology. 2015,1263, 243-250, https://doi.org/10.1007/978-1-4939-2269-7_19.

12. Luo, S.; Lenon, G.B.; Gill, H.; Hung, A.; Dias, D.A.; Li, M.; Nguyen, L.T. Inhibitory effect of a weight-loss Chinese herbal formula RCM-107 on pancreatic $\alpha$-amylase activity: Enzymatic and in silico approaches. Plos One 2020, 15, https://doi.org/10.1371/journal.pone.0231815.

13. Farzaneh, S.; Zarghi, A. Estrogen receptor ligands: a review (2013-2015). Scientia Pharmaceutica. 2016, 84, 409-427, https://doi.org/10.3390/scipharm84030409.

14. Naganuma, M.; Yokoo, H.; Misawa, T.; Matsuno, K.; Tsuji, G.; Demizu, Y. Design and synthesis of 4-(2pyrrolyl)-4-phenylheptane derivatives as estrogen receptor antagonists. Heterocycles 2020, 101, 429-434, https://doi.org/10.3987/COM-19-14121.

15. Amenyogbe, E.; Chen, G.; Wang, Z.; Lu, X.; Lin, M.; Lin, A.Y. A review on sex steroid hormone estrogen receptor in mamals and fish. International Journal of Endocrinology 2020, 2020, https://doi.org/10.1155/2020/5386193.

16. Xu, Y.; Feng, L.; Jeffrey, P.D.; Shi, Y.; Morel, F.M.M. Structure and metal exchange in the cadmium carbonic anhydrase of marine diatoms. Nature 2008, 452, 56-62, https://doi.org/10.1038/nature06636.

17. Imtaiyaz Hassan, M.; Shajee, B.; Waheed, A.; Ahmad, F.; Sly, W.S. Structure, function and applications of carbonic anhydrase isozymes. Bioorganic \& Medicinal Chemistry, 2013, 21, 1570-1582, https://doi.org/10.1016/j.bmc.2012.04.044.

18. Suksamrarn, A.; Ponglikitmongkol, M.; Wongkrajang, K.; Chindaduang, A.; Kittidanairak, S.; Jankam, A.; Yingyongnarongkul, B.E.; Kittipanumat, N.; Chokchaisiri, R.; Khetkam, P.; Piyachaturawat, P. Diarylheptanoids, new phytoestrogens from the rhizomes of Curcuma comosa: isolation, chemical modification and estrogenic activity evaluation. Bioorganic \& Medicinal Chemistry 2008, 16, 6891-6902, https://doi.org/10.1016/j.bmc.2008.05.051

19. Jongkon, N.; Tangyuenyongwatana, P. Molecular binding modes of diarylheptanoids from Curcuma comosa on the ER $\beta$ - receptor. The Thai Journal of Pharmaceutical Sciences 2014, 38, 82-89.

20. Mohammadhassan, R.; Fallahi, S.; Mohammadalipour, Z. ADMET and pharmaceutical activity analysis of caffeic acid derivatives by in silico tools. Letter in Applied NanoBioScience 2020, 9, 840-848, https://doi.org/10.33263/LIANBS91.840848. 